\title{
AGRICULTURA DE PRECISÃO NO ESTUDO DA FERRUGEM DO CAFEEIRO CONILON
}

\author{
Jorge Tadeu Fim Rosas ${ }^{1}$ \\ Vinícius Agnolette Capelini ${ }^{2}$ \\ Samira Luns Hatum de Almeida ${ }^{3}$ \\ Gabriel Dias de Oliveira ${ }^{4}$ \\ Willian Bucker Moraes ${ }^{5}$ \\ Julião Soares de Souza Lima ${ }^{6}$ \\ Samuel de Assis Silva ${ }^{7}$
}

\begin{abstract}
Resumo: objetivou-se com esse trabalho correlacionar de forma espacial, a incidência média da ferrugem do cafeeiro conilon com a massa de casca estraida dos grãos secos. O experimento foi conduzido em uma área de aproximadamente 2 ha, cultivada comercialmente com plantas de café conilon, para o levantamento das informações de incidência da ferrugem e da massa de casca seca por hectare, foi montado na área um grid irregular totalizando 120 pontos amostrais, os pontos amostrais foram georreferenciados com auxílio de uma estação total. As variáveis em estudo apresentaram dependencia espacial, foram construidos variogramas com patamares bem definidos, e posteriormente foi construido mapas temáticos de distribuição espacial. A média da incidência da ferrugem avaliada ao longo do ano não se correlacionou com a massa de casca produzida pela lavoura. A massa de casca apresentou variação de 0,3 a 2,3 Mg.ha-1, sendo que a maior parte da área teve produção de casca inferior a 1,5 Mg.ha-1, com destaque para a região central da área, que apresentou os maiores valores de massa.
\end{abstract}

Palavras-chave: Hemileia vastatrix; geoestatística; café conilon.

\footnotetext{
1 Departamento de Engenharia Rural/Universidade Federal do Espírito Santo, Brasil, e-mail: jorgetadeufimrosas@hotmail.com.

2 Departamento de Engenharia Rural/Universidade Federal do Espírito Santo, Brasil, e-mail: vinicius91ac@hotmail.com.

3 Departamento de Engenharia Rural/Universidade Federal do Espírito Santo, Brasil, e-mail: samiraluns@hotmail.com.

4 Departamento de Engenharia Rural/Universidade Federal do Espírito Santo, Brasil, e-mail: gabriel.dias.oliveira@gmail.com.

5 Departamento de produção vegetal/Universidade Federal do Espírito Santo, Brasil, e-mail: willian.moraes@ufes.br.

6 Departamento de Engenharia Rural/Universidade Federal do Espírito Santo, Brasil e-mail: limajss@yahoo.com.br.

7 Departamento de Engenharia Rural/Universidade Federal do Espírito Santo, Brasil, e-mail: sasilva@pq.cnpq.br.
} 